\title{
APLIKASI PEMBELAJARAN HAND LETTERING UNTUK PEMULA BERBASIS ANDROID
}

\author{
Ayub Amheka1, Little Queen²
}

\begin{abstract}
Abstrak :
Manusia membutuhkan media untuk berkomunikasi, salah satunya adalah melalui tulisan.Tulisan menjadi aspek penting dalam semua bidang yang berhubungan dengan manusia, di bidang pendidikan, bidang perkantoran, termasuk bidang seni. Hand lettering menjadi cara sederhana untuk berkomunikasi. Hand lettering terdiri atas dua jenis yaitu kaligrafi dan lettering.Kaligrafi adalah seni menulis indah sedangkan lettering pada dasarnya adalah menggambar, dengan huruf sebagai objek utamanya.Hand Letter digunakan untuk mengilustrasikan tanda-tanda, seperti tanda-tanda jalan, tag harga, dan lain-lain, yang mana kata-katanya ditulis atau digambarkan menggunakan tangan dan bukan dicetak. Manfaat hand lettering bagi masyarakat antara lain adalah bermanfaat untuk perkembangan otak anak-anak baik secara fisik maupun mental dan juga melatih motorik dan keterampilan visual. Smartphone berbasis android bisa dijadikan sebagai media pembelajaran sederhana, proses belajar dapat dilakukan kapan dan di mana saja, Dengan adanya aplikasi mobile berbasis android dapat membantu orang-orang yang baru saja mulai mempelajari hand lettering atau yang telah mempelajarinya agar proses belajar tersebut menjadi lebih terarah dan efektif.
\end{abstract}

Kata Kunci : Hand Lettering, Kaligrafi, Lettering, Smartphone, Android, Aplikasi Mobile.

\section{PENDAHULUAN}

Sebagai mahluk sosial manusia pada dasarnya memiliki kebutuhan dan kemampuan untuk berkomunikasi dengan lingkungan sekitar yaitu dengan manusia lainnya. Hal ini membuat manusia membutuhkan media untuk berkomunikasi, salah satunya adalah melalui tulisan. Semakin berkembangnya zaman tulisan menjadi beragam, tulisan menjadi aspek penting dalam semua bidang yang berhubungan dengan manusia, di bidang pendidikan, bidang perkantoran, termasuk bidang seni.

Hand lettering menjadi cara sederhana untuk berkomunikasi dan menyampaikan informasi dalam bentuk ekspresi seni yang tak terbatas. Seni bagaimana mengeksplorasi 26 karakter huruf secara konsisten menjadi sesuatu yang indah dilihat secara visual. Hand lettering terdiri atas dua jenis yaitu kaligrafi dan lettering. Kaligrafi adalah seni menulis indah sedangkan lettering pada dasarnya adalah menggambar, dengan huruf sebagai objek utamanya.

Hand Lettering digunakan untuk mengilustrasikan tanda-tanda, seperti tanda-tanda jalan, tagihan harga, dan lain-lain, yang mana kata-katanya ditulis atau digambarkan menggunakan tangan dan bukan dicetak.

Manfaat hand lettering bagi masyarakat antara lain adalah bermanfaat untuk perkembangan otak anak-anak baik secara fisik maupun mental dan juga melatih motorik dan keterampilan visual, berdasarkan riset dari Indiana University menulis dengan tangan dapat menstimulus ide-ide baru, hand lettering yang telah diaplikasikan dengan mural juga berfungsi sebagai dekorasi-dekorasi ruangan, hand lette- 


\section{Jurnal Ilmiah FLASH Volume 2 Nomor 1 Juni 2016}

ring juga digunakan sebagai desain fashion, dengan manfaat tersebut maka hand lettering dapat berguna sebagai salah satu alat pengembangan SDM.

Saat ini hand lettering sedang sangat berkembang, beberapa komunitas hand lettering didirikan untuk mengakomodasi orang-orang yang tertarik untuk mempelajari hand lettering, tempat berbagi pengalaman, keterampilan, dan yang terpenting memperluas seni hand lettering.

Dengan adanya komunitas ini orang-orang yang ingin belajar mendapat tempat bernaung dan lebih terarah dalam menekuni hand lettering. Dibandingkan dengan hal itu, ada orangorang yang ingin mempelajari hand lettering, namun karena keterbatasan daerah tempat tinggal yang tidak mempunyai komunitas hand lettering, tidak adanya koneksi atau teman yang mempunyai minat yang sama yaitu hand lettering, membuat orang-orang ini terpaksa harus belajar sendiri atau otodidak. Dengan hanya berbekal kegemaran akan seni, keingintahuan, dan sedikit pengetahuan tentang hand lettering itu sendiri orang-orang ini mulai melakukan hand lettering.

Para pemula ini belajar melalui buku ataupun Internet. Hal ini menjadi masalah karena dengan begitu hanya orang yang mampu membeli buku saja yang bisa belajar, ataupun hanya orang yang mempunyai koneksi internet yang bisa belajar. Selanjutnya itu juga menjadi masalah karena buku-buku tersebut harus dibawa ke mana-mana yang mana hal tersebut menjadi tidak efisien, dan menjadi lebih sulit untuk dibagi ke orang lain, lalu untuk yang belajar melalui internet hal tersebut akan sulit bagi pemula karena internet terlalu luas, terlalu banyak sumber sehingga para pemula tersebut tidak tahu harus mulai dari mana dan tidak terarah. Keterbatasan tersebut membuat proses mempelajari hand lettering ini menjadi lebih lambat.

Smartphone bisa dijadikan sebagai media pembelajaran sederhana, proses belajar dapat dilakukan kapan dan dimana saja. Perangkat mobile memiliki ukuran yang kecil, orangorang menginginkan perangkat yang terkecil untuk kenyamanan dan mobilitas mereka. Perangkat mobile menghabiskan sedikit daya dibandingkan dengan mesin desktop.

Untuk mengatasi beberapa hal di atas yang menjadi kendala dalam mempelajari hand lettering, maka dibutuhkan sebuah pedoman untuk memberikan pengetahuan bagi para pemula ini, yaitu tentang Apa itu hand lettering? Bagaimana melakukannya? Apa saja alat-alat yang dibutuhkan?

Dengan adanya aplikasi mobile berbasis android ini dapat membantu orang-orang yang baru saja mulai mempelajari hand lettering atau yang telah mempelajarinya agar proses belajar tersebut menjadi lebih terarah dan efektif.

\section{TINJAUAN PUSTAKA}

Untuk penelitian ini penulis telah melakukan beberapa kajian atas penelitian terdahulu yang relevan dengan penelitian penulis, yaitu : a.Hendra, dkk. (2013). Rancang Bangun Aplikasi Pembelajaran Iqra Berbasis Android. Pada penelitian tersebut dijelaskan bahwa Metodologi yang digunakan dalam pembuatan aplikasi ini ialah metodologi waterfall. Tujuan dari pembuatan aplikasi ini diharapkan dapat membantu anak-anak untuk bisa mengenal huruf-huruf hijaiyah, gambar objek disertai dengan nama objek dalam bahasa Arab dan Indonesia, dapat membedakan harakat dan cara pengucapannya. Aplikasi ini memiliki kemampuan antara lain fitur arah kiblat dan belajar Iqra sebagai fitur menulis huruf hijaiyah dengan menggunakan draw canvas, aplikasi ini juga mampu menampilkan gambar objek disertai dengan nama objek dalam bahasa Arab dan Indonesia, serta cara pengucapan harakat.

b.Sumita, dkk. (2015). Aplikasi Pembelajaran Kebudayaan dan Ilmu Agama Hindu di Indonesia Berbasis Android. Aplikasi ini dibangun sebagai media alternatif pembelajaran dan pemberitaan informasi mengenai Agama Hindu. Aplikasi ini dibangun dengan menggunakan metodologi prototype. Aplikasi berbasis Android ini dilengkapi dengan fiturfitur penjelasan mengenai kebudayaan dan 
ilmu Agama Hindu, selain itu terdapat juga fitur komunitas yang dapat digunakan sebagai forum diskusi dan pemberitaan antar umat Agama Hindu, fitur kalender yang dapat digunakan untuk melihat penanggalan Agama Hindu, fitur map yang dapat digunakan untuk menampilkan peta lokasi pura-pura yang ada di Indonesia dan juga terdapat fitur kuis (pilihan ganda, tebak kata dan mencocokkan) sebagai media untuk pembelajaran bagi pengguna aplikasi sehingga pengguna tidak jenuh dalam proses pembelajaran. Pada tahap ini desain aplikasi pembelajaran dengan menggunakan Eclipse, SDK dan ADT serta PHP.

\section{METODE PENELITIAN}

a. Metode Obervasi

Observasi dilakukan dengan menganalisa terhadap sistem serta aspek-aspek lain yang dapat mempengaruhi terhadap jalannya sistem baik dari sisi lingkungan maupun dari sisi pengguna sistem itu sendiri.

b.Metode Studi Pustaka

Metode studi kepustakaan dilakukan untuk menunjang metode observasi yang telah dilakukan. Pengumpulan informasi yang dibutuhkan dilakukan dengan mencari referensi-referensi yang berhubungan dengan penelitian yang dilakukan, referensi dapat diperoleh dari buku-buku atau internet.

c. Model Perancangan Sistem

Metode yang digunakan dalam pembuatan Aplikasi Pembelajaran Hand Lettering Untuk Pemula Berbasis Android adalah metode Waterfall, yang terdiri dari :

Analisa Kebutuhan

\section{a. Alat}

Perangkat keras yang digunakan adalah Laptop dengan processor Intel Core 2 duo 2.4GHz, RAM 2GB DDR3 serta hard drive 500GB.

\section{b.Bahan}

Perangkat lunak yang digunakan pada komputer untuk mengembangkan Aplikasi Pembelajaran Hand Lettering Untuk
Pemula Berbasis Android adalah sebagai berikut:

1.Windows 7 sebagai sistem operasi komputer.

2.Eclipse ADT.

3.Adobe Photoshop CS5.

4.Adobe Illustrator CS6.

c. Kebutuhan Input

Adapun kebutuhan input dari Aplikasi

Pembelajaran Hand Lettering Untuk

Pemula Berbasis Android antara lain :

1.Materi 4 jenis kaligrafi; Copperplate, Blackletter, Faux, dan Italic, berupa video, gambar, dan teks.

2.Materi lettering berupa video, gambar, dan teks

d.Kebutuhan output dari Aplikasi Pembelajaran Hand Lettering Untuk Pemula Berbasis Android antara lain :

1.Mampu menampilkan video langkahlangkah membuat kaligrafi berdasarkan tipe kaligrafi.

2.Mampu menampilkan gambar dan teks langkah-langkah membuat kaligrafi untuk masing-masing alphabet.

3.Mampu menampilkan video, gambar dan teks langkah-langkah membuat lettering.

Desain Sistem

a. Unified Modeling Language

1.Use Case Diagram

2.Activity Diagram

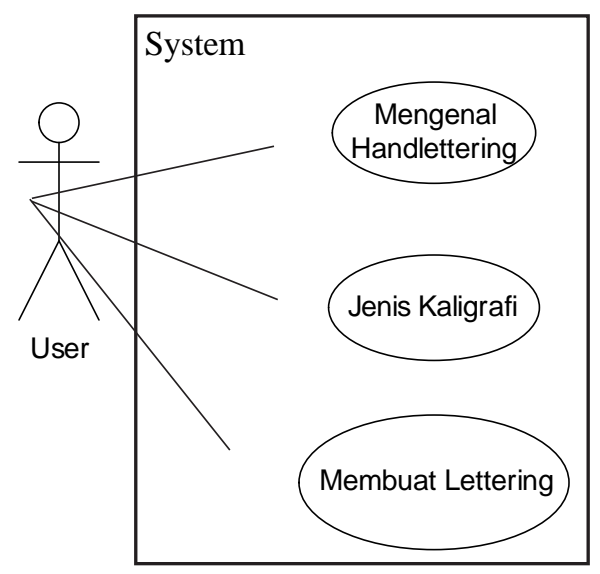

Gambar 1. Use Case Diagram 


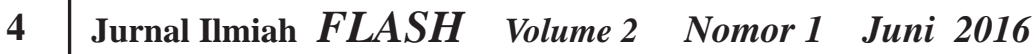

Tabel 1. Use Case Mengenal Hand Lettering

\begin{tabular}{|c|c|c|}
\hline $\begin{array}{c}\text { Nama } \\
\text { Use } \\
\text { Case }\end{array}$ & \multicolumn{2}{|c|}{ Mengenal Hand Lettering } \\
\hline Actors & User & \multicolumn{1}{|c|}{ System } \\
\hline & $\begin{array}{l}\text { 1. Memilih } \\
\text { menu Hand } \\
\text { Lettering }\end{array}$ & \\
\cline { 3 - 3 } Skenario & & $\begin{array}{l}\text { 2. Menampilkan isi } \\
\text { Nonu Hand } \\
\text { Lettering }\end{array}$ \\
\hline
\end{tabular}

Tabel 2. Use Case Jenis Kaligrafi

\begin{tabular}{|c|c|c|}
\hline $\begin{array}{l}\text { Nama } \\
\text { Use }\end{array}$ & \multicolumn{2}{|c|}{ Jenis Kaligrafi } \\
\hline Actors & User & System \\
\hline \multirow{6}{*}{$\begin{array}{c}\text { Skenario } \\
\text { Normal }\end{array}$} & $\begin{array}{l}\text { 1. Memilih } \\
\text { menu } \\
\text { Kaligrafi }\end{array}$ & \\
\hline & & $\begin{array}{l}\text { 2. Menampilkan } \\
\text { jenis Kaligrafi }\end{array}$ \\
\hline & $\begin{array}{l}\text { 3. Memilih } \\
\text { salah satu } \\
\text { jenis Kali- } \\
\text { grafi. }\end{array}$ & \\
\hline & & $\begin{array}{l}\text { 4. Menampilkan isi } \\
\text { dari jenis kali- } \\
\text { grafi yang dipilih } \\
\text { yaitu Alat \& Ba- } \\
\text { han dan Cara } \\
\text { Membuat. }\end{array}$ \\
\hline & $\begin{array}{l}\text { 5. Memilih } \\
\text { menu Alat \& } \\
\text { Bahan } \\
\end{array}$ & \\
\hline & & $\begin{array}{l}\text { 6. Menampilkan isi } \\
\text { menu Alat \& } \\
\text { Bahan }\end{array}$ \\
\hline \multirow[b]{2}{*}{$\begin{array}{c}\text { Skenario } \\
\text { Alter- } \\
\text { natif }\end{array}$} & $\begin{array}{l}\text { 5. b. Memilih } \\
\text { menu Cara } \\
\text { Membuat }\end{array}$ & \\
\hline & & $\begin{array}{l}\text { 7. Menampilkan } \\
\text { daftar alphabet } \\
\text { dari cara mem- } \\
\text { buat jenis kali- } \\
\text { grafi yang dipilih }\end{array}$ \\
\hline
\end{tabular}

\begin{tabular}{|l|l|l|}
\hline \multirow{2}{*}{} & $\begin{array}{l}\text { 8. Memilih } \\
\text { salah satu } \\
\text { alphabet }\end{array}$ & \\
\cline { 2 - 3 } & & $\begin{array}{l}\text { 9. Menampilkan isi } \\
\text { alphabet yang } \\
\text { dipilih. }\end{array}$ \\
\hline
\end{tabular}

Tabel 3. Use Case Membuat Lettering

\begin{tabular}{|c|c|c|}
\hline $\begin{array}{l}\text { Nama } \\
\text { Use }\end{array}$ & \multicolumn{2}{|c|}{ Membuat Lettering } \\
\hline Actors & User & System \\
\hline \multirow{4}{*}{$\begin{array}{c}\text { Skenario } \\
\text { Normal }\end{array}$} & $\begin{array}{l}\text { 1. Memilih } \\
\text { menu } \\
\text { Lettering }\end{array}$ & \\
\hline & & $\begin{array}{l}\text { 2. Menampilkan isi } \\
\text { dari Lettering } \\
\text { Alat \& Bahan } \\
\text { dan Cara } \\
\text { Membuat. }\end{array}$ \\
\hline & $\begin{array}{l}\text { 3. a. Memilih } \\
\text { menu Alat } \\
\text { \& Bahan }\end{array}$ & \\
\hline & & $\begin{array}{l}\text { 4. Menampilkan isi } \\
\text { menu Alat \& } \\
\text { Bahan }\end{array}$ \\
\hline \multirow{2}{*}{$\begin{array}{l}\text { Skenario } \\
\text { Altematif }\end{array}$} & $\begin{array}{l}\text { 3. b. Memilih } \\
\text { menu Cara } \\
\text { Membuat }\end{array}$ & \\
\hline & & $\begin{array}{l}\text { 5. Menampilkan isi } \\
\text { dari menu Cara } \\
\text { membuat }\end{array}$ \\
\hline
\end{tabular}

Berikut ini adalah activity diagram "Mengenal Hand Lettering

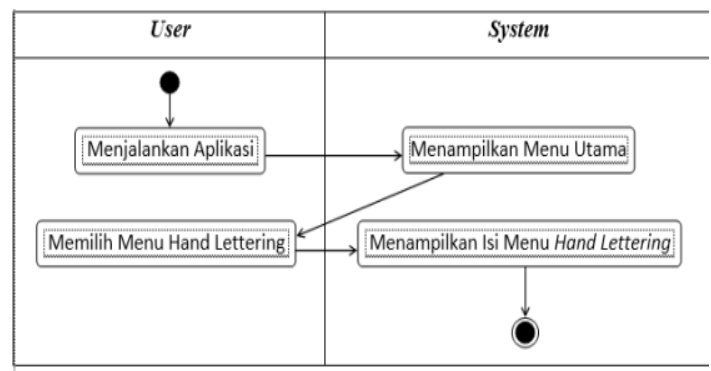


Berikut ini adalah activity diagram

"Jenis Kaligrafi"

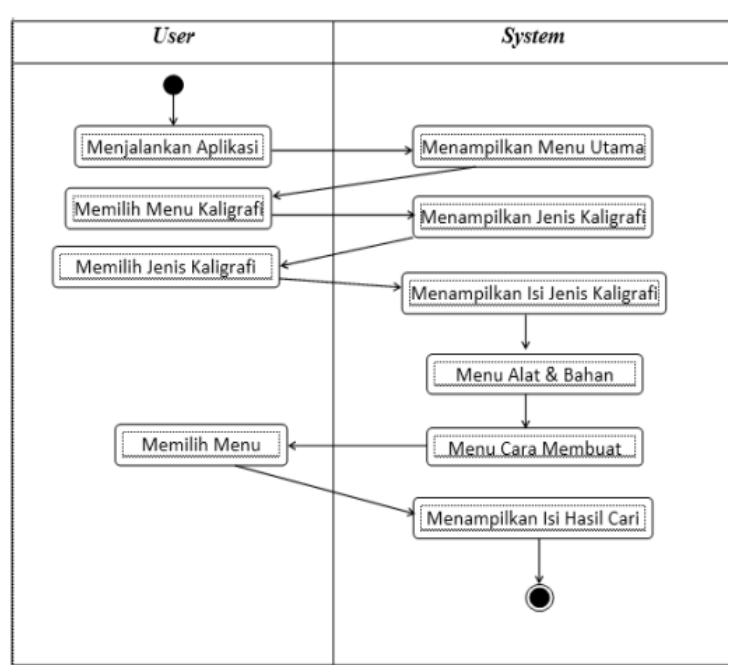

Berikut ini adalah activity diagram "Membuat Lettering"

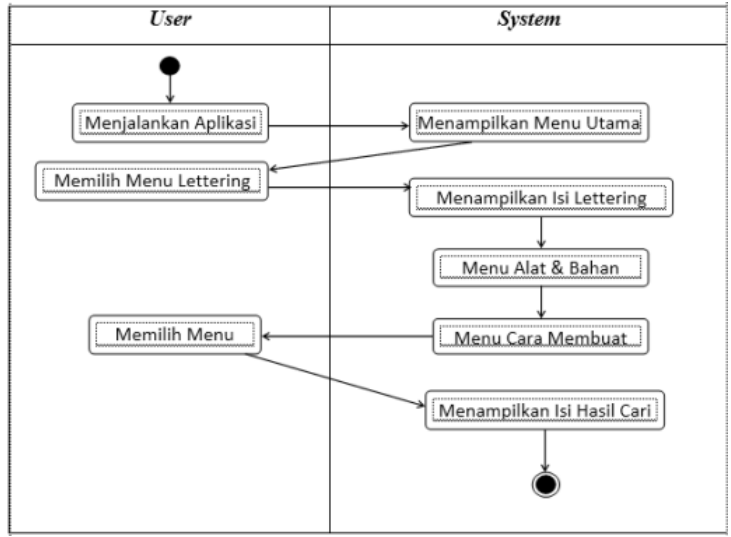

3.Sequence Diagram

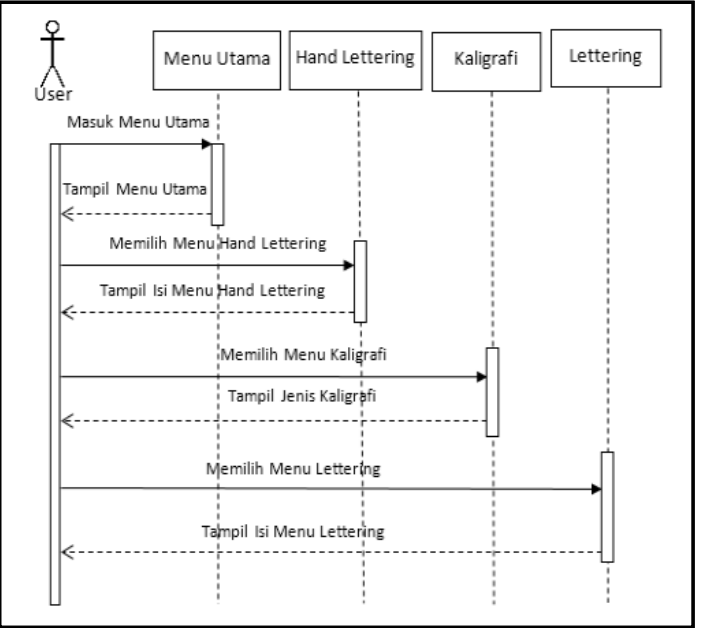

Sequence Diagram di atas ketika user membuka aplikasi maka aplikasi akan merespon dan masuk ke tampilan Menu Utama.

Selanjutnya jika user memilih menu hand lettering maka responnya adalah menampilkan halaman isi dari menu tersebut. Kemudian jika user memilih menu kaligrafi maka akan direspon dengan tampilan jenis kaligrafi. Lalu jika user memilih menu lettering maka akan direspon dengan menampilkan halaman isi menu lettering. 


\section{Jurnal Ilmiah FLASH $\quad$ Volume 2 Nomor 1 Juni 2016}

4.Class Diagram

Pada Class Diagram sistem akan menampilkan sistem kelas, atribut, dan hubungan antar kelas.

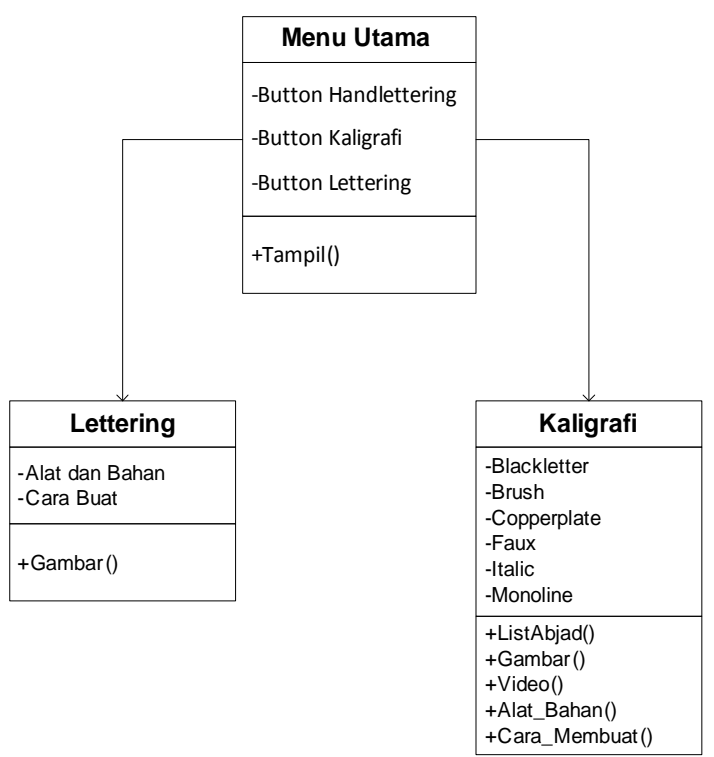

\section{HASIL DAN PEMBAHASAN}

1. Implementasi Hand Lettering

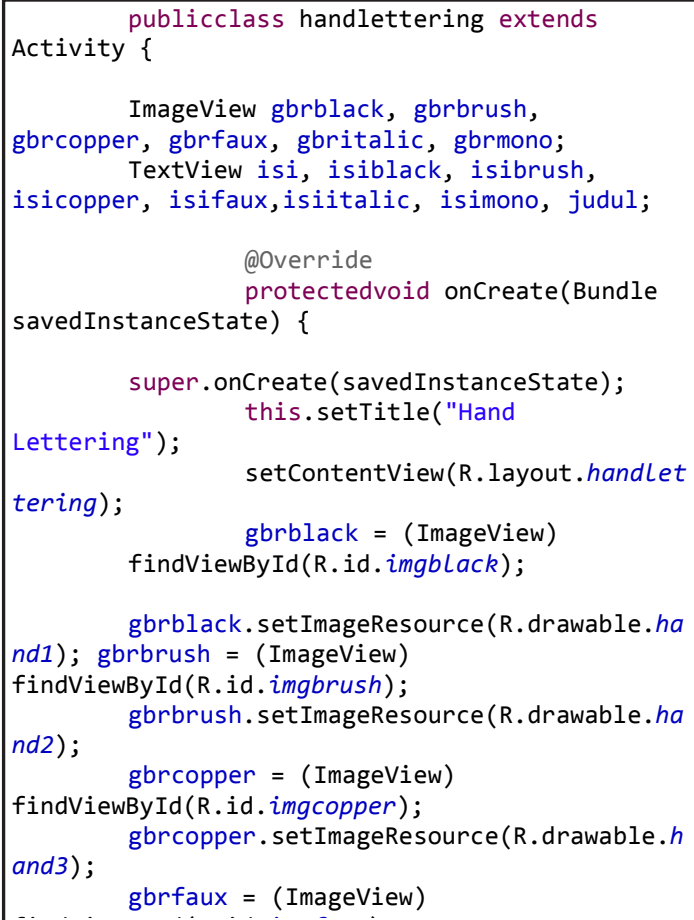

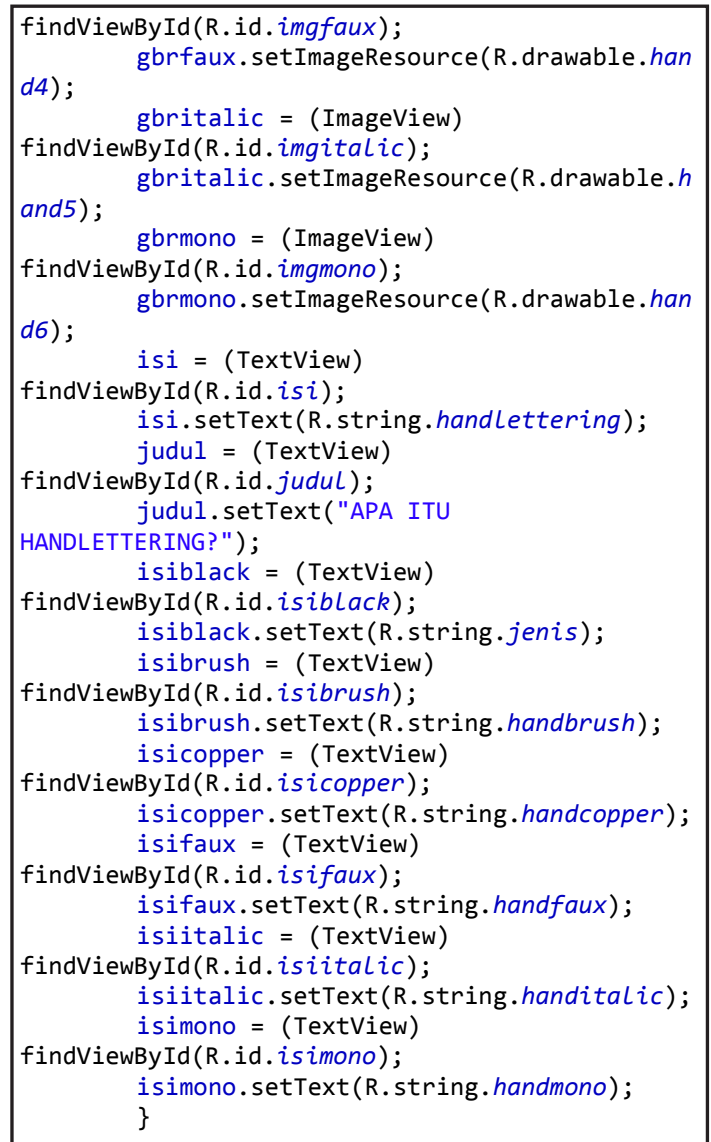

Gambar 2. Implementasi Hand Lettering

Gambar 2 merupakan implementasi kode program dari Hand Lettering yang berisi gambar dan teks.

Implementasi Kaligrafi

Daftar Abjad

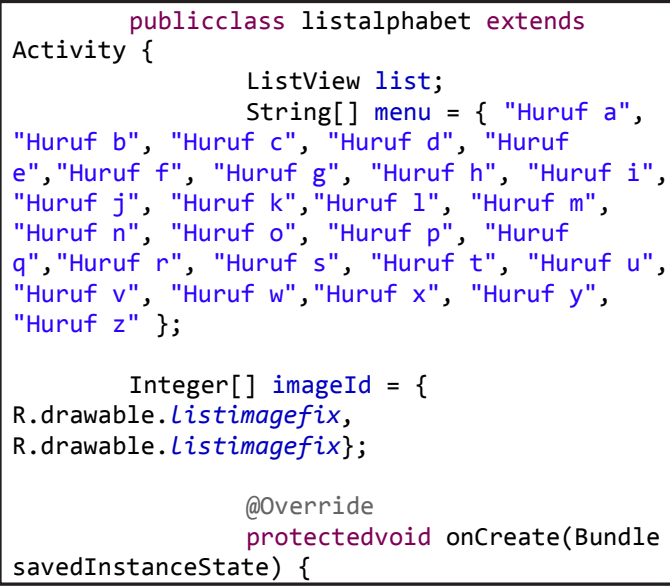




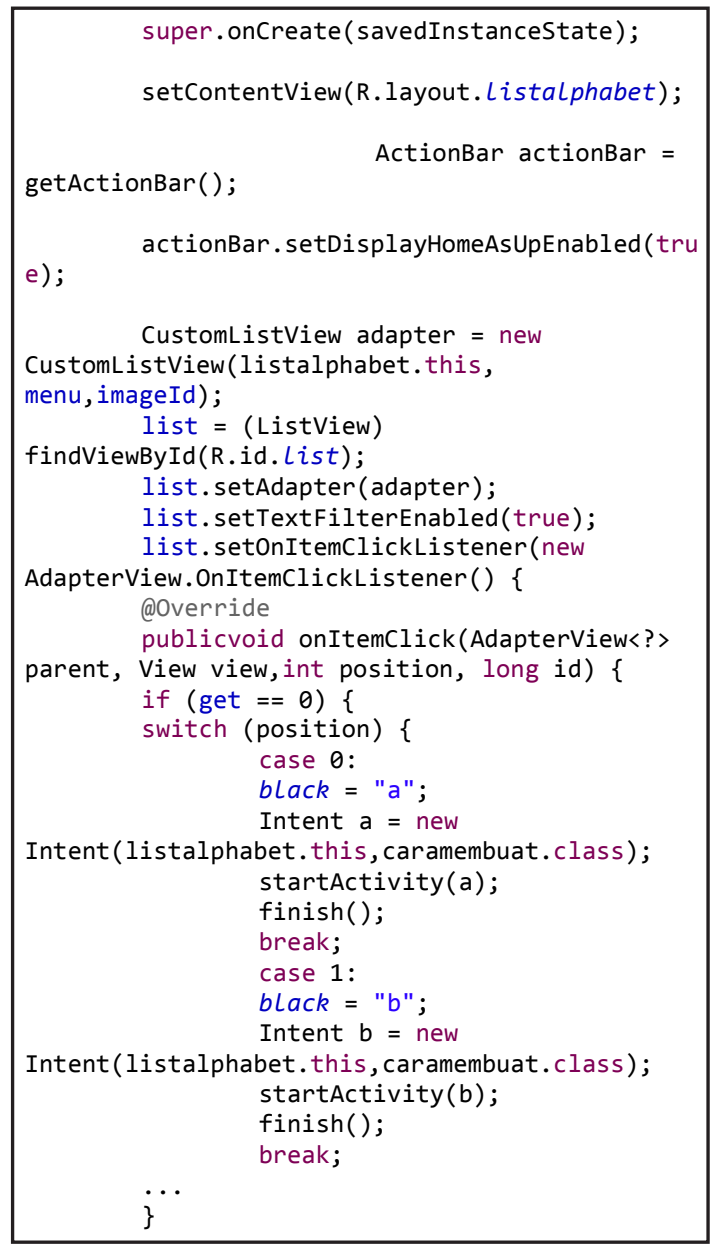

Gambar 3. Implementasi Daftar Abjad

Pada gambar 3 merupakan implementasi kode yaitu menggunakan ListView untuk menampilkan abjad huruf dari jenis kaligrafi yang dipilih.

\section{Gambar}

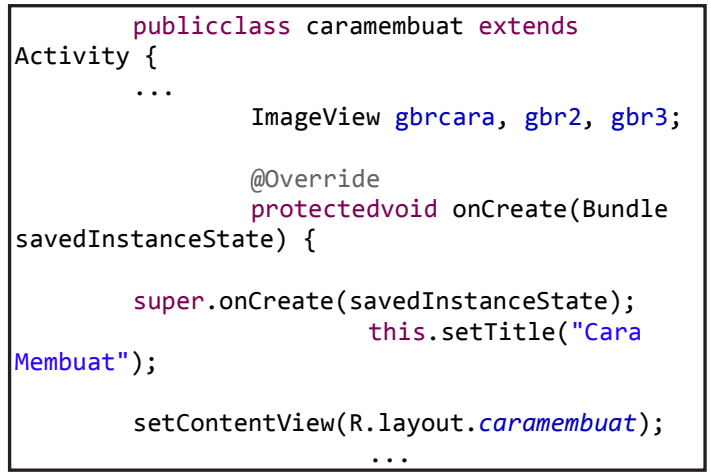

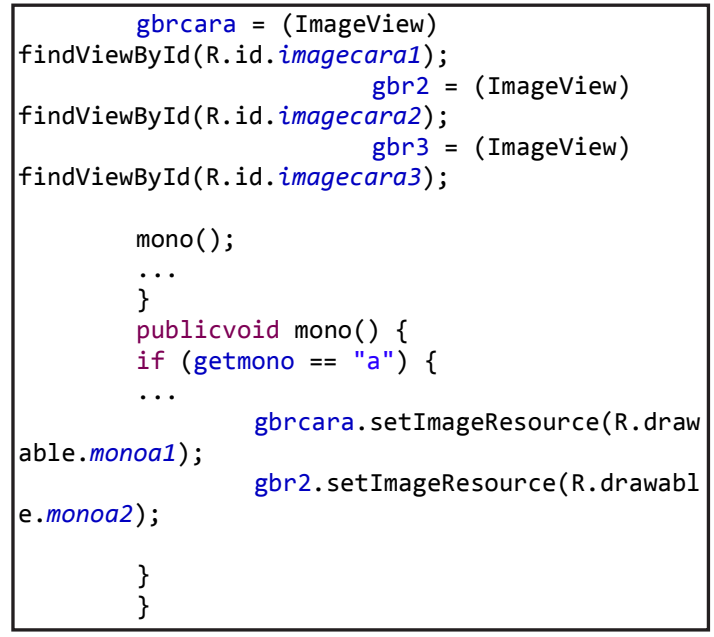

Gambar 4. Implementasi Gambar

Gambar di atas adalah implementasi kode program untuk menampilkan gambar pada aplikasi.

\section{Video}

Activity \{

publicclass VideoViewActivity extends

intget = tabkaligrafi. $b ;$
ProgressDialog pDialog;
VideoView videoview;
@override
protectedvoid onCreate(Bundle

savedInstanceState) \{

super.onCreate(savedInstancestate);

this.setTitle("Kaligrafi");

setContentView(R.layout.activity_video_

view);

videoview $=$

(VideoView) findViewById(R.id.videoView1); pDialog $=$ new

ProgressDialog(VideoViewActivity.this);

pDialog.setTitle("Video Cara Membuat");

pDialog.setMessage("Buffering...");

pDialog.setIndeterminate (false); pDialog.setMax(50);

pDialog.setCancelable(true); pDialog.show (); video();

$\dddot{j}$

publicvoid video() \{ 


\section{Jurnal Ilmiah FLASH $\quad$ Volume 2 Nomor 1 Juni 2016}

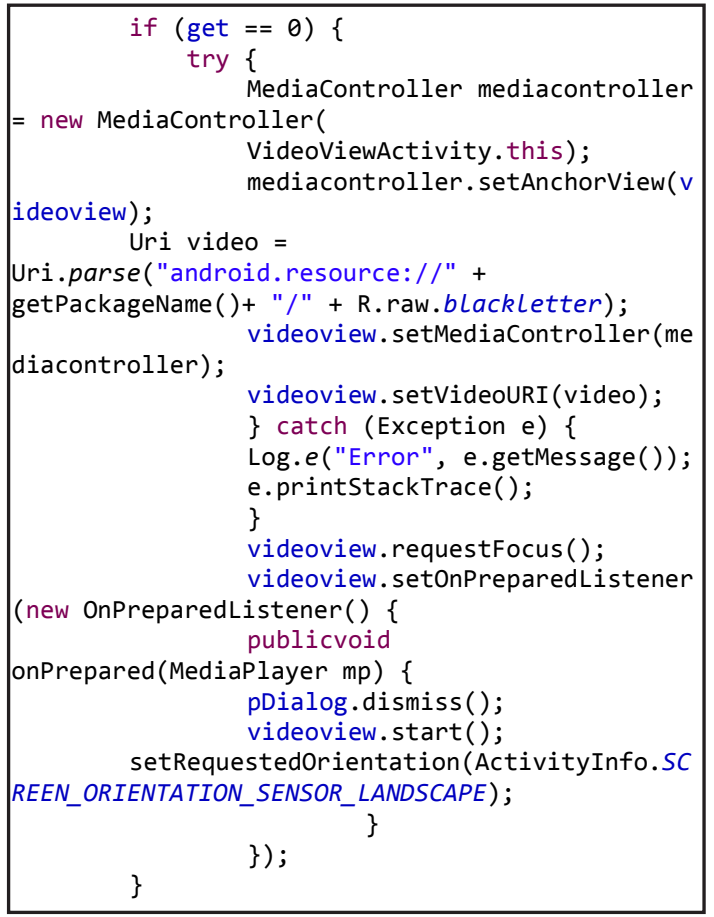

Gambar 5. Implementasi Video

Gambar 5 merupakan implementasi kode program yang menggunakan Video View dan Media Controller untuk menampilkan video pada aplikasi.

\section{Implementasi Lettering}

Teks dan Animasi

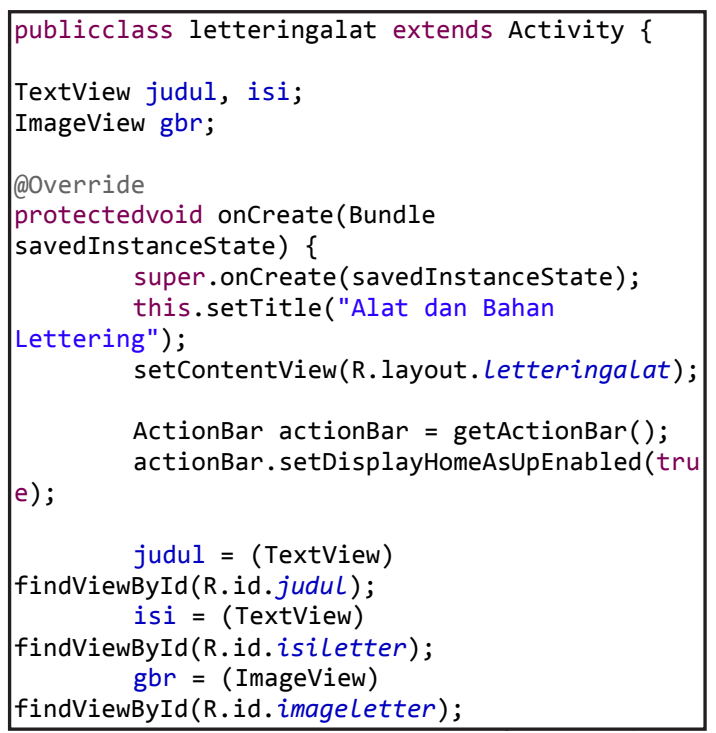

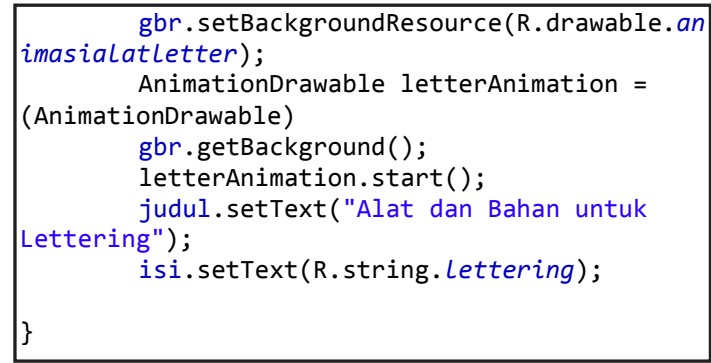

Gambar 6. Implementasi Teks dan Animasi Gambar di atas menunjukan implementasi kode program yang menampilkan animasi gambar dan teks.

\section{Hasil}

Manual Program

\section{Splash Screen dan Tampilan Menu}

Splash screen merupakan tampilan awal setelah pengguna mulai menjalankan aplikasi atau menekan icon Hand Lettering.

Menu awal adalah tampilan pertama aplikasi setelah splash screen, dalam activity ini pengguna di suguhkan 3 tombol yang masingmasing berbeda fungsinya, berikut tampilannya:

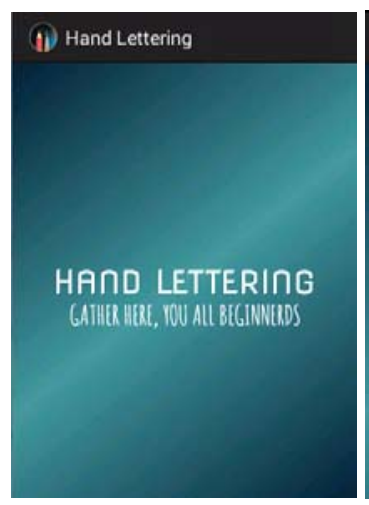

Gambar 7. Splash Screen

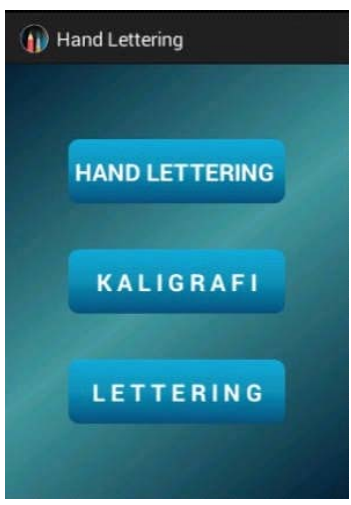

Gambar 8. Menu Utama
Gambar 7 Splash Screen Gambar 8 Menu Utama

Tombol-tombol tersebut dengan fungsi sebagai berikut : 
a. Hand Lettering

Saat tombol ditekan maka akan mengantarkan user ke tampilan isi menu Hand Lettering.

b.Kaligrafi

Saat tombol ini ditekan maka akan berpindah ke halaman kaligrafi yang berisi jenis-jenis kaligrafi.

c. Lettering

Dengan menekan tombol ini maka akan berpindah ke tampilan menu Lettering yang berisi menu Alat dan Bahan juga Cara Membuat Lettering.

\section{Menu Hand Lettering}

Pada menu ini berisi penjelasan mengenai Hand Lettering itu sendiri; apa itu Hand Lettering dan jenis-jenisnya.

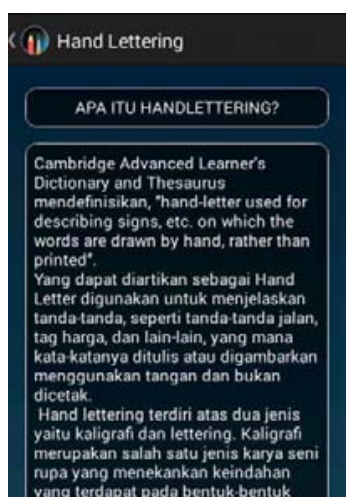

Gambar 9. Hand Lettering (1).

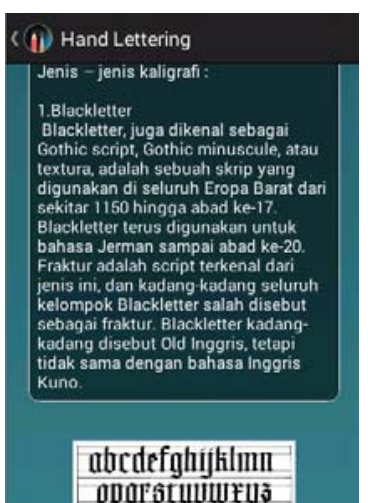

Gambar 10. Hand Lettering (2).

\section{Menu Kaligrafi}

Pada menu ini terdapat pilihan jenis-jenis kaligrafi, diantaranya adalah Blackletter, Brush, Copperplate, Faux, Italic, dan Monoline.Masing-masing dari jenis kaligrafi tersebut memiliki menu didalamnya yaitu Alat-Bahan, Cara Membuat, dan Video.

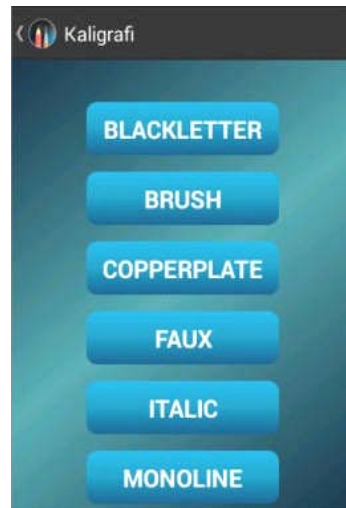

Gambar 11. Menu Kaligrafi

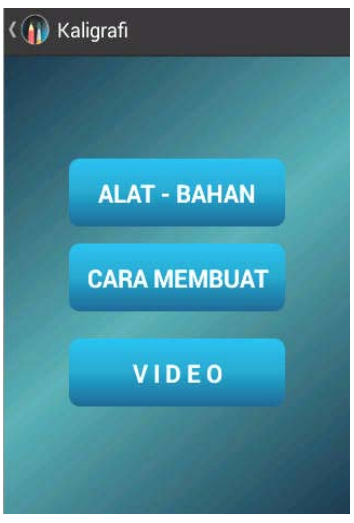

Gambar 12. Isi Menu Kaligrafi

\section{Alat-Bahan}

Pada menu ini terdapat deskripsi alat dan bahan yang diperlukan untuk melakukan Hand Lettering.

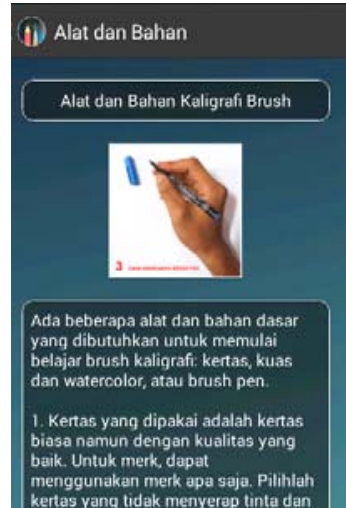

Gambar 13. Isi AlatBahan (1).

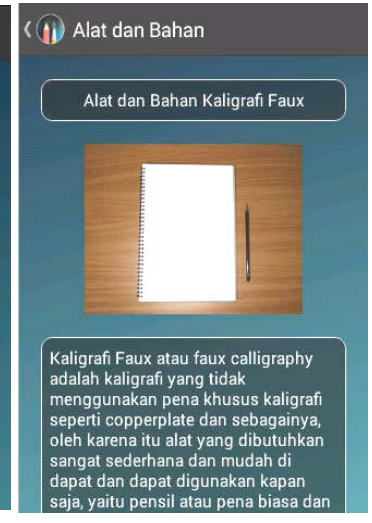

Gambar 14. Isi AlatBahan (2).

\section{Cara Membuat}

Pada Menu ini terdapat daftar huruf a-z, yang mana ketika salah satu dari huruf tersebut dipilih maka akan berpindah ke tampilan isi cara membuat huruf tersebut dari jenis kaligrafi yang dipilih. 


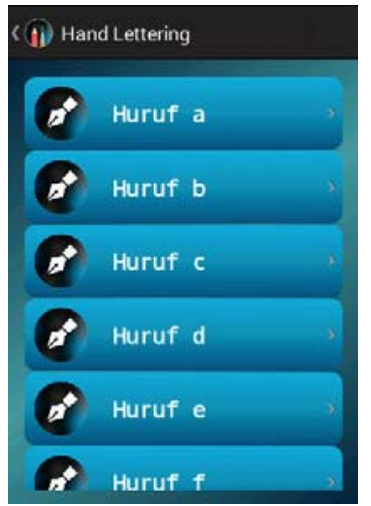

Gambar 15. Daftar Huruf

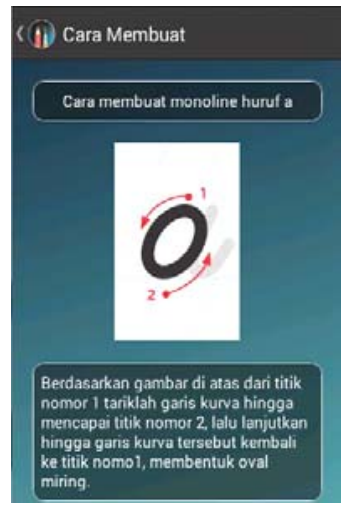

Gambar 16.

Tampilan Isi Huruf

Video

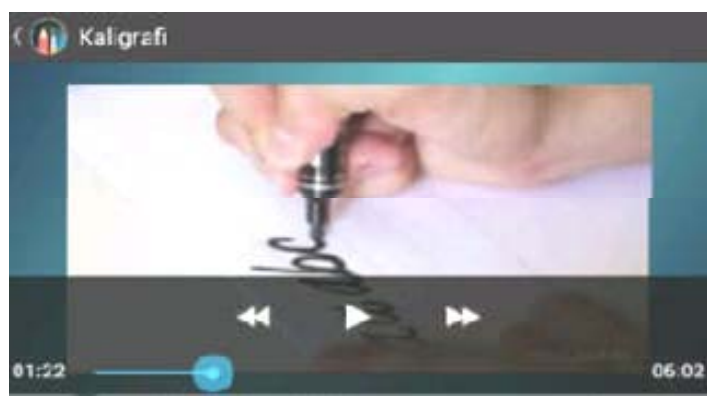

Gambar 17. Tampilan Video

\section{Menu Lettering}

Pada menu ini terdapat 2 tab yang mana tab yang 1 adalah Alat dan Bahan, sedangkan tab yang lainnya adalah tab Cara Membuat.

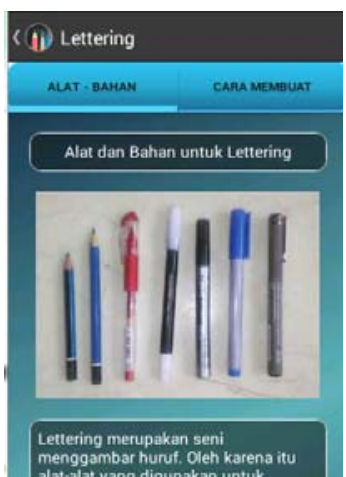

Gambar 18. Tampilan Alat-Bahan Lettering

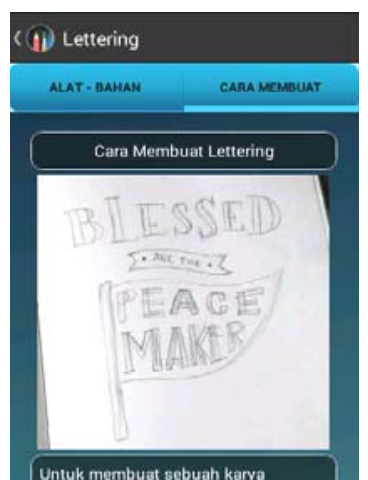

Gambar 19. Tampilan Cara Membuat Lettering

\section{Pembahasan}

Hand lettering dapat berguna sebagai salah satu alat pengembangan SDM, untuk perkembangan otak anak-anak baik secara fisik maupun mental dan juga melatih motorik dan ketrampilan visual, hand lettering yang telah diaplikasikan dengan mural juga berfungsi sebagai dekorasi-dekorasi ruangan, hand lettering juga digunakan sebagai desain fashion. dengan manfaat-manfaat tersebut Hand Lettering sebagai salah satu bidang menjadi penting dan berguna. Dengan adanya smarthphone berbasis Android yang saat ini mempunyai peran penting karena sudah dapat berfungsi sebagai alat bantu pembelajaran, kedua hal ini menjadi kombinasi hebat yang dapat membantu perkembangan SDM juga perkembangan dalam dunia seni. Untuk itu diperlukan adanya aplikasi yang membantu proses belajar tersebut. Aplikasi Hand Lettering ini merupakan solusi yang tepat.

\section{Uji Coba Sistem}

Aplikasi Daiko Sunday School ini telah diinstal dan dijalankan ke beberapa smartphone Android dengan berbagai merk dan juga OS Android, juga ukuran layar yang berbeda. Berikut ini tabel hasil pengujian sistemnya :

Tabel 4. Pengujian Sistem

\begin{tabular}{|c|c|c|c|c|}
\hline $\begin{array}{c}\mathrm{N} \\
\text { o }\end{array}$ & $\begin{array}{c}\text { Merk } \\
\text { Smart } \\
\text { phone }\end{array}$ & $\begin{array}{c}\text { Versi } \\
\text { OS }\end{array}$ & $\begin{array}{c}\text { Ukuran } \\
\text { Layar }\end{array}$ & Keterangan \\
\hline 1 & $\begin{array}{c}\text { Asus } \\
\text { ZenFone } \\
\text { Go }\end{array}$ & $\begin{array}{c}\text { Android } \\
\text { Lolipop 4.5 }\end{array}$ & $4.5 "$ & $\begin{array}{c}\text { Aplikasi Hand Lettering } \\
\text { bisa berjalan. Semua } \\
\text { tombol bisa berfungsi. } \\
\text { Tampilan Sesuai. }\end{array}$ \\
\hline 2 & $\begin{array}{c}\text { Samsung } \\
\text { Galaxy V }\end{array}$ & $\begin{array}{c}\text { Android } \\
\text { Kitkat 4.4 }\end{array}$ & $4 "$ & $\begin{array}{c}\text { Aplikasi Hand Lettering } \\
\text { bisa berjalan. Semua } \\
\text { tombol bisa berfungsi. } \\
\text { Tampilan Sesuai. }\end{array}$ \\
\hline 3 & $\begin{array}{c}\text { Samsung } \\
\text { Galaxy } \\
\text { Grand } \\
\text { Prime }\end{array}$ & $\begin{array}{c}\text { Android } \\
\text { Lolipop 4.5 }\end{array}$ & $5 "$ & $\begin{array}{c}\text { Aplikasi Hand Lettering } \\
\text { bisa berjalan. Semua } \\
\text { tombol bisa berfungsi. } \\
\text { Tampilan Sesuai. }\end{array}$ \\
\hline 4 & $\begin{array}{c}\text { Asus } \\
\text { ZenFone 2 } \\
\text { Laser }\end{array}$ & $\begin{array}{c}\text { Android } \\
\text { Lolipop 4.5 }\end{array}$ & $5 "$ & $\begin{array}{c}\text { Aplikasi Hand Lettering } \\
\text { bisa berjalan. Semua } \\
\text { tombol bisa berfungsi. } \\
\text { Tampilan Sesuai. }\end{array}$ \\
\hline 5 & $\begin{array}{c}\text { Asus } \\
\text { ZenFone 2 } \\
\text { Selfie }\end{array}$ & $\begin{array}{c}\text { Android } \\
\text { Lolipop 4.5 }\end{array}$ & $5.5 "$ & $\begin{array}{c}\text { Aplikasi Hand Lettering } \\
\text { bisa berjalan. Semua } \\
\text { tombol bisa berfungsi. } \\
\text { Tampilan Sesuai. }\end{array}$ \\
\hline
\end{tabular}




\section{PENUTUP}

\section{Kesimpulan}

Dalam pembuatan aplikasi Hand Lettering ini diharapkan dapat memberikan pendidikan, kemudahan, efisien, efektif, bagi yang mau belajar Hand Lettering. Sebagai akhir laporan, dapat ditarik kesimpulan sebagai berikut :

a. Aplikasi ini dapat berjalan di device smartphone Android versi Jelly Bean dan versi setelahnya.

b.Aplikasi ini berbahasa Indonesia sehingga belum bisa dipakai secara universal.

c. Aplikasi yang dikemas secara modern, yaitu dengan smartphone Android, agar proses belajar Hand Lettering lebih mudah.

\section{Saran}

Berdasarkan penelitian dan analisis hasil, terdapat beberapa saran untuk perbaikan sistem selanjutnya. Saran-saran tersebut diantaranya adalah:

a. Untuk membuat aplikasi yang baik dan efektif, sebaiknya dikerjakan dalam tim sehingga dapat berbagi tugas, ada yang bertugas untuk mendesain, ada yang bertugas sebagai programmer dan pembagian tugas lainnya, sehingga aplikasi dapat diselesaikan dengan cepat dan efektif.

b.Dalam pengembangan aplikasi ini masih menggunakan Bahasa Indonesia, harapan ke depannya bahwa aplikasi ini dapat dikembangkan dan dapat digunakan secara universal dengan bahasa universal.

c. Semoga kedepannya aplikasi ini dapat dikembangkan menjadi lebih dinamis dan lebih menarik.

d.Aplikasi sebaiknya dikembangkan dengan menambahkan fitur seperti area pencarian agar dapat lebih mempermudah proses belajar Hand Lettering.

\section{DAFTAR PUSTAKA:}

Bausenhardt, Julia. 2015. A Beginner's Guide to Modern Calligraphy. http://juliabausenhardt.com/a-beginners-guide-to-moderncalligraphy/. 23 Agustus 2016.

Cambridge Advanced Learner's Dictionary \& Thesaurus.2016. Hand-lettered. http:// dictionary.cambridge.org/dictionary/ english/hand-lettered.16 Agustus 2016.

Hendra, M; Ramadhany, A. 2013. Rancang Bangun Aplikasi Pembelajaran Iqra Berbasis Android.STMIK MDP.http://eprints. mdp.ac.id/id/eprint/782. 23 Agustus 2016.

Kimianto, Eko. 2009. Pengertian Kaligrafi Secara Umum. http://artkimianto. blogspot. co.id/2009/06/pengertian-kaligrafi-secaraumum.html. 14 Agustus 2016.

Miranti. 2015. Paper And Ink. https://www. livingloving.net/2015/craft/resources/ paper-and-ink/. 14 Agustus 2016.

Raharjo, B; Heryanto, I; Haryono, A. 2010. Tuntunan Pemograman Java Untuk Handphone Dan Alat Telekomunikasi Mobile. Informatika. Bandung.

Safaat, Nazruddin. 2012. Pemrograman Aplikasi Mobile Smartphone dan Tablet PC Berbasis Android. Informatika. Bandung.

Sumita, I. K; Candra, D; Yoannita.2015. Aplikasi Pembelajaran Kebudayaan dan Ilmu Agama Hindu di Indonesia Berbasis Android. STMIK GI MDP.http://eprints.mdp.ac.id/id/ eprint/1417. 23 Agustus 2016.

Wikipedia. 2016. Blackletter.https:// en.wikipedia.org/wiki/Blackletter. 23 Agustus 2016.

Wikipedia. 2016. Copperplate.https://en. wikipedia.org/wiki/Copperplate_script. 23 Agustus 2016.

Wikipedia. 2016. Italic. https://en. wikipedia. org/wiki/Italic script. 23 Agustus 2016. 